\title{
La Psicología de Vigotski en la enseñanza preescolar
}

agomez@lasallep.edu.mx

Enrique García González

Trillas, 2006

Hablar de educación en nuestro tiempo es hacer referencia a los grandes iniciadores del constructivismo, enfoque educativo que busca transformar la enseñanza centrándola en el alumno y en la construcción propia del aprendizaje. Desde esta perspectiva las aportaciones de Jean Piaget y Liev Vigostki son las más determinantes y divulgadas.

En efecto, ambas teorías hacen aportaciones respecto a la inteligencia, el lenguaje, el aprendizaje y la enseñanza, pero desde una perspectiva diferente; el primero lo hace partiendo del enfoque biológico-cognitivo; y el segundo propone un enfoque sociocultural-cognitivo, en el cual los aspectos culturales del medio reciben una mayor importancia. Así, el texto propone un análisis de las aportaciones de Vigostki en relación a la educación preescolar y al trabajo con los niños y adolescentes discapacitados, considerando que las deficiencias orgánicas son suplidas por unas fuerzas psíquicas y por la zona de desarrollo proximal* que puede ayudar a potenciar otras áreas del desarrollo, compensando así la discapacidad.

Para Vigotski el juego es una forma de entender el desarrollo de la inteligencia, es por ello que las actividades propuestas en la educación preescolar tendrían que centrarse en el juego, ya que permite al niño comprender su mundo y su realidad cultural interiorizando las experiencias sensibles, asimismo el autor propone varias actividades a realizar por parte del maestro para que el niño construya y refuerce la imaginación y creatividad que conformarán las bases para la zona de desarrollo proximal.

La zona de desarrollo proximal es la distancia entre el nivel real de desarrollo, determinada por la capacidad de un individuo de resolver independientemente un problema o tarea, y el nivel de desarrollo potencial, a través de la resolución de un problema o tarea mediante la interacción de un mediador o compañero más experimentado. Evidentemente la teoría vigotskiana está centrada en la zona de desarrollo proximal; sin embargo, es importante hacer referencia a las otras dos zonas, la real y la potencial, que ocupan un espacio reducido en el texto, ahora bien para quien ha seguido al autor se podrá dar cuenta que en el libro Vigotski: La formación de la psique, se desarrollan con mayor profundidad los elementos 
estructurales de la teoría vigostskiana, sería importante considerarlos para tener una mayor concreción en el desarrollo de las actividades del pedagogo.

* Cf. García González, Enrique. La psicología de Vigotski en la enseñanza preescolar. Pag. 11

En la propuesta pedagógica que se plantea ampliamente en el capítulo 12; ahí se busca un desarrollo mental en sus cuatro áreas: atención, percepción, abstracción y memoria, para ello hay que buscar que las experiencias logren ser significativas para el niño mediante la interacción social y el condicionamiento cultural de la labor pedagógica, trabajando la sensibilización, apropiación y construcción. Con estos elementos pueden madurar en el niño los procesos cognitivos a través de la promoción de las artes expresivas, la narrativa y expresión corporal.

Dado que el texto está pensado para la formación de los niños en preescolar considero que sería de mucha utilidad para los alumnos de las licenciaturas en pedagogía y ciencias de la educación, para desarrollar las prácticas de intervención en este nivel escolar, ya que da pauta para el diseño de actividades. Asimismo, el texto proporciona un sustento teórico a las propuestas pedagógicas en relación con el niño de 0 a 5 años; una ventaja más, es la importancia que textos de éste tipo tienen en cuanto nos permiten comprender el complejísimo fenómeno en que consiste la educción preescolar, ya que durante la educación preescolar se da la adquisición de los mecanismos necesarios para resolver los retos futuros. Al mismo tiempo, otra ventaja del texto es que nos indica cómo trabajar con niños con capacidades diferentes, esto gracias a sus estudios realizados con sordomudos 